\title{
Avaliação e Perspectivas em Ciência e Tecnologia na Área de Engenharia de Produção
}

\begin{abstract}
RESUMO: Este artigo apresenta uma avaliação das atividades de ensino e pesquisa em Engenharia de Produção desenvolvidas nos cursos de graduação e pós-graduação e grupos de pesquisa em nosso país. São apresentadas previsões para o desenvolvimento econômico e industrial na próxima década, $e$ a posição e evolução da Engenharia de Produção nesse cenário. É apresentado um conjunto de sugestōes e recomendações para a capacitação tecnológica dos pesquisadores, assim como as áreas prioritárias de ação neste periodo.
\end{abstract}

ABSTRACT: Production Engineering research practice in Brazil is reviewed, emphasizing the activities developped by graduation and post-graduation courses, and research groups.

This paper presents an assessment of Production Engineering teaching activities and research lines subjects, pointing out the various modifications and evolution ocurred on these fields.

Global economics scenarios forecasts for the next decade are introduced and evaluated, in oder to predict Production Engineering position and evolution in this period. A set of suggestions and recommendations are presented on the subjects of personnel improvement, new courses formation and priorities for operation and investment.

Palavras-chave: Engenharia de Produção, avaliação setorial no Brasil, pesquisa e ensino.

Key words: Production Engineering, Brazilian sectorial appraisal, research and courses.

\author{
Anamaria de Morais (ABERGO) \\ Celso L. Pereira Rodrigues (UFPb) \\ José A. do N. Pinto (UFSM) \\ Luiz Fernando Nanni (UFRGS) \\ Paulo Renato de Morais (INPE) \\ Rabah Behakouche (UFSC) \\ Raul Valentim da Silva (ABEPRO) \\ Ricardo Miranda Barcia (UFSC)
}




\section{Introdução}

Este trabalho insere-se no programa Avaliação e Perspectivas (A\&P), promovido e $c 0$ ordenado pelo Conselho Nacional de Desenvolvimento Científico e Tecnológico (CNPq), que objetiva a explicitação das principais tendências e demandas nas diversas áreas de conhecimento, sendo destinado a servir de referência para o planejamento das ações das entidades de pesquisa, do CNPqe das demais agências de fomento. Em sua concepção foram colocadas ênfases em reflexões prospectivas sobre o desenvolvimento da Engenharia de Produção na próxima década, tendo como apoio os cenários projetados para o Brasil pela área de planejamento do BNDES [1],e como ponto de partida o diagnóstico da situação atual.

Os trabalhos de elaboração do documento foram iniciados em meados de 1988, envolvendo os cursos de pós-graduação da área e a Associação Brasileira de Engenharia de Produção (ABEPRO), tendo como relatores os professores Leonardo J. Lustosa (CA/ $\mathrm{CNPq}$ ) e Itiro Iida (ABEPRO). Na ocasião foram coletadas, através de questionários, informações sobre os cursos de graduação e pós-graduação. A primeira versão do documento foi debatida no VIII Encontro Nacional de Engenharia de Produção (ENEGEP), em setembro de 1988, na cidade de São Carlos. Uma segunda versão foi apresentada pelos relatores em abril de 1989 [2], sendo aprovada no IX ENEGEP realizado em setembro na cidade de Porto Alegre, na forma de proposta de Programa de Desenvolvimento da Engenharia de Produção para a próxima década.

$O$ texto aprovado serviu de base para a definição do presente documento que teve como relator o Prof. Ricardo Miranda Barcia, indicado pelo $\mathrm{CNPq}$, sendo promovidas as devidas atualizaçōese efetuadooenquadramento na atual metodologia do programa
A\&P. Para a reunião de elaboração do texto final, realizada nos dias 20 e 21 de novembro de 1989, em Florianópolis, foram convidados os coordenadores dos cursos de pós-graduação em Engenharia de Produção, o Prof. Paulo Renato de Morais (CA/CNPq) eos representantes das associações que têm maiores vinculações com a Engenharia de Produção: ABEPRO, ABERGO (Ergonomia) e SOBRAPO (Pesquisa Operacional).

Uma das diretrizes fundamentais do programa A\&P estabelece que os documentos resultantes devam ser utilizados como um efetivo instrumento de planejamento, gerando um processo com atuação de forma permanente. Para a implementação desta importante diretriz foi mantida no presente documento a recomendação, já aprovada pela ABEPRO, de constituição de um grupo permanente de acompanhamento e avaliação da área de Engenharia de Produção.

\section{Análise da Situação Atual}

\section{HISTÓRICO SUCINTO DA ÁREA}

Criada nos Estados Unidos no início do século atual, com o nome de Engenharia Industrial, a área só foi introduzida no ensino formal na década de 50, no Brasil, com o nome de Engenharia de Produção(EP). Esta denominação foi padronizada, para o ensino, pela resolução n-o 10/77 do Conselho Federal de Educação. Nas empresas, principalmente de origem estrangeira, ainda se usa freqüentemente o termo Engenharia Industrial, como sinônimo.

Na concepção do American Institute of Industrial Engineers, utilizada pela ABEPRO, compete à Engenharia de Produção o projeto, a melhoria e a implantação de sistemas integrados envolvendo homens, materiais e equi- 
pamentos, cabendo especificar, prever e avaliar os resultados obtidos nestes sistemas, recorrendo a conhecimentos especializados de matemática, física e ciências sociais, conjuntamente com os princípios e métodos de análise e projeto da engenharia.

A Engenharia de Produção, desde a sua origem, tem recebidouma grande influência norte-americana. Ela difundiu-se em diversos países americanos como curso formalmente organizado, o que não aconteceu em outras regiões. Na Europa, por exemplo, são poucos os programas acadêmicos que reúnem os elementos de conhecimentos e os objetivos característicos da EP, existindo exceções como na França e na Ingla terra onde, nos últimosdez anos, a EP tem tido apreciável desenvolvimento.

No Brasil, o primeiro curso em nivel de graduação foi criado em 1957 na Escola Politécnica da Universidade de São Paulo, como opção do curso de Engenharia Mecânica. Só em 1966 surgiu o primeiro curso de pós-graduação, em nível de mestrado, na Pontifícia Universidade Católica do Rio de Janeiro, logo seguido pelo da COPPE/UFRJ, em 1967. Em 1972 foram criados os cursos de doutorado na EPUSP e na COPPE/UFRJ.

Em 1982, havia dezesseis cursos de graduação, sete de mestrado e dois de doutorado. A pesar das várias mudanças ocorridas, apenas em 1989 estas estatísticas foram alteradas com a implantação do doutoramento na UFSC

\section{CURSOS}

\section{GRADUAÇÃO}

Existem hoje, no Brasil, dezesseis cursos de graduação em Engenharia de Produção, dos quais quatorze organizados segundo os moldes da Resolução n-o 10/77 do Conselho Federal de Educação, que estabeleceu a EP como habilitação específica, com origem em qualquer outra grande área da Engenharia (Civil, Mecânica, Elétrica, Química, Metalúrgica ou de Minas). Existem ainda os cursos da EPUSP e da UFRJ que, por serem anteriores à Resolução n-o 10/77, são organizados de forma independente de qualquer outra área da Engenharia. Finalmente, existem alguns cursos que se estruturam como ênfases de Engenharia deProdução,em outrasáreas da Engenharia.

É interessante notar que, apesar de um tanto singular, a organização estabelecida pelo CFE tem se mostrado acertada. Os poucos cursos que, no Brasil, têm uma organização independente de outras áreas da Engenharia já identificaram a dificuldade de tratar a EP sem referência explícita a alguma área tecnológica. A formação do engenheiro de produção com uma sólida base de conhecimento em alguma área da Engenharia de Projeto tem sido também recomendada nos Estados Unidos. Esta parece ser uma forma de assegurar um vínculo tecnológico, sem o qual a Engenharia de Produção perde uma de suas importantes características que é a atuação nas interfaces da tecnologia com a Administração, a Economia, a Psicologia Industrial, a Matemática A plicada, a Computaçãoe as outras disciplinas de que se utiliza.

A oferta de empregos para engenheiros de produção cresceu substancialmente nos últimos dez anos. O número de graduados não acompanhou esse crescimento em função do pequeno aumento do número de vagas ocorrido nesse período.

Apesar dos avanços obtidos por vários cursos em relação à situação em 1981, conforme se constata nos Encontros Nacionais de Engenharia de Produção(ENEGEP) realizados anualmente, desde então algumas deficiências permanecem. Destacam-se entre elas: (a) insuficiência de livros didáticos nacionais; (b) pouca integração com o setor produtivo; 
(c) baixa capacitação acadêmica de docentes em algumas subáreas e instituições e (d) desatualização dos cursos em função dos rápidos avanços da automação industrial e da informática.

\section{PÓS-GRADUAÇÃO}

Em nivel de pós-graduação, seis cursos de mestrado relacionados na "Avaliação e Perspectivas 1982" permanecem até hoje e o sétimo, o da UFPE, interrompeu suas atividades. O curso da Universidade Federal Fluminense foi oúnico que surgiu desde então. As Universidades Federais de São Carlos, do Rio Grande doSul, da Bahia e de Minas Gerais cogitam a abertura de novos cursos de mestrado, mas as dificuldades encontradas são diversas. Nos dois programas de doutora mento existentes em 1982 (EPUSP e COPPE/ UFRJ) foram recentemente incluídas outras áreas de concentração além de Pesquisa Operacional. Apenas em 1989 foi implantado o terceiro doutoramento da área na Universidade Federal de Santa Catarina. A PUC/RJ, apesar de ter planos de criar seu doutorado, não deverá efetivá-los antes de 1991.

A demanda pelo mestrado tem crescido, principalmente nos últimos anos, mas o número de titulados tem evoluído lentamente. A colocação dos egressos tem sido boa, mesmo para os que não chegam a se titular, defendendo dissertação. A baixa taxa de titulação (relação entre alunos titulados sobre admitidos) é um fator preocupante. Essa taxa varia, dependendo do curso, de $10 \%$ a cerca de $50 \%$.

A alta taxa de desistências sempre foi um problema para os cursos de mestrado, pois muitos alunos procuram na EP apenas uma forma de mudar as suas qualificaçōes profissionais, em relação aos cursos de graduação realizados. Um diagnóstico mais detalhado deste fenômenoé importante para reformular e dimensionar a estrutura de cursos de graduação, pós-graduação, strictosensu, latosensu e extensão.

O quadro de docentes não se expandiu mas teve uma pequena melhoria em qualidade. Os programas com quadros mais qualificados (UFSC, UFSM, EPUSP, UFF, UFRJ e PUC/RJ) têm hoje $50 \%$ ou mais de seus quadros formados por doutores ou equivalentes.

Em 1982, apenas a EPUSP e a UFRJ atingiam ou superavam essa proporção.

A situação dos quadros docentes é, de um modo geral, preocupante, pelas seguintes razões:

a) existem programas com uma significativa taxa de doutores com idade média elevada e com muito pouco pessoal em treinamento. Sendo a contratação de doutores já formados muito difícil, isto representa um sério risco de deterioração futura da competência desses quadros;

b) a procura por cursos de doutorado no exterior tem sido muito baixa e, mesmo somada às reduzidas possibilidades de formação no País não será suficiente para repor as perdas naturais;

c) uma futura retomada do crescimento econômico brasileiro irá, certamente, produzir uma ação predatória do setor produtivo sobre as Universidades, contratando seus melhores talentos;

d) os avanços em áreas afins como Informática e Engenharia Mecânica (decorrentes da automação industrial, novos produtos e novos materiais) têm se refletido na necessidade de atualizar os professores/pesquisadores da EP. A reciclagem dos atuais docentes e a contratação de novos elementos com esses conhecimentos não têm ocorrido em ritmo suficiente para atualizar os quadros, retardando o avanço de importantes linhas de pesquisa e a evolução dos currículos. 


\section{PESQUISA}

As subáreas da EP identificadas na "Avaliação e Perspectivas 1982" sofreram alteraçōes apreciáveis nas suas linhas de pesquisa.

\section{Gerência de Produção}

Nota-se um substancial crescimento relativo dos seguintes aspectos:

Garantia de Qualidade - Entendida de um modo amplo (qualidade total), que se integra com aspectos de organização do trabalho, projeto do produto e controle do processo produtivo.

Organização da Produção - Novas formas de aplicação de técnicas tradicionais, tais comoProgramaçãoda Produção, "Lay-out" celular e Análise de Valores, além da ênfase noenfoque sócio-técnico, na metodologia de pesquisa-ação no planejamento participativo.

Organização do Trabalho - Ênfase em formas pós-tayloristas de organização do trabalho, empregando-se técnicas como rotação de cargos, círculos de controle de qualidade $\mathrm{e}$ participação do operário nas decisões.

Condições de Trabalho - Situações de periculosidade, insalubridadee dificuldade (física ou mental).

Planejamento e Controle Integrado de Manufaturas-Planejamento de Recursos de Manufaturas (MRP II), Controle Integrado de Manufatura (CIM) e outros ligados à automação flexível.

Gestão Tecnológica - Esteé um tema considerado incipiente em 1982 que vem se afirmando através de ramificações de outras subáreas. Incluem-se nesta linha os estudos do impacto econômico e social de novas tecnologias, a adaptação das organizações às mudanças tecnológicas e os efeitos da automação sobre a organização do trabalho e sobre o trabalhador. Este tema abrange também aspectos políticos, econômicos einstitucionais do desenvolvimento científico e tecnológico e da difusão e transferência de tecnologias.

Pesquisa Operacional

Observa-se uma tendência de ampliação do escopo da PO para intensificar as aplicaçōes clássicas e criar novas aplicações.

Implementação - Maior preocupação em produzir protótipos implementáveis em computadores, particularmente em microcomputadores.

Novas Metodologias - Utilização de Sistemas Especialistas e outras técnicas de Inteligência Artificial.

Aplicações - Organização de esforços em torno de aplicações.

Integração - Integrar modelos, dados e técnicas de solução em sistemas de apoio à tomada de decisão.

\section{Engenharia Econômica}

Há uma tendência de expansão em outras especialidades, reduzindo-se a importânciadas aplicações clássicas de matemática financeira.

Projetos Industriais - Maior ênfase em considerações de risco, aspectos institucionaise ligação com outros níveis de planejamento (planejamento setorial, planejamento regional).

Finanças - Maior ênfase na análise de mercados financeiros econsiderações explícitas do risco.

Engenharia de Produto

Há uma tendência de abandonar as linhas metodológicas gerais e concentrar esforços em 
estudos e aplicações mais específicos integrando os diversos aspectos de projeto e produção.

Projeto com Auxílio de Computador 'Computer Aided Design' (CAD), associado ao 'Computer Aided Manufacturing' (CAM), e integração com processos automatizados de produção.

Adaptação do Produto às Necessidades do Mercado, à Capacidade Instalada das Empresas e às Características do Operador/ Usuário - Política do produto, pesquisa do consumidor, testes e avaliaçōes de produtos.

Outras linhas de pesquisa associadas à EP também evoluíram:

\section{Sistemas de Transporte}

Apesar de, do ponto de vista da EP, não haver razão para se privilegiar os serviços de transportes sobre outras divisões do setor de serviços, a PUC/RJ e, mais recentemente, a UFSC têm mantido linhas de pesquisa e deespecialização em transportes. O planejartẹ̣o projeto e a operação de sistemas de transportes são objetos de ensinoe de pesquisa com metodologias semelhantes às das demais subáreas.

\section{Gerenciamento da Construção Civil}

É outra área associada à Engenharia Civil que vem sendo agregada à Engenharia de Produção principalmente na UFF, na UFGRS e na UFSC.

Os esforços desenvolvidos na área da Engenharia Civil visam adaptar os conceitos de Engenharia de Produção à realidade do processo produtivo e do planejamento da Construção Civil, merecendo destaque as áreas de Organização e Condições de Trabalho, Gerenciamento da Produção, Custos Industriais, Controle do Processo e do Produto, CAD, Gestão Tecnológica e Análise de
Riscos e Viabilização de Empreendimentos de Engenharia.

\section{Cenário Futuro}

Os cenários de apoio ao presente trabalho, elaborados pelo BNDES, consideram as perspectivas sobre a evolução sócio-conômica em nível nacional e internacional, tendo como referência o limiar do século XXI. As variações previsíveis nos fatores econômicos, sociais e tecnológicos, visualizadas através de cenários de longo prazo, foram interpretadas no contexto da Engenharia de Produção.

O cenário de Integração Competitiva, de ocorrência mais provável, identifica uma oportunidade histórica para que o Brasil possa colocar-se, no final dos anos 90, no rol das nações desenvolvidas. À Engenharia de Produção cabe um papel de destacada importância neste cenário, tanto nas metas relativas à dinamização e à expansão do mercado interno, como especialmente na conquista de significativos espaços no mercado mundial. As grandes preocupações da área de Engenharia de Produção, incluindo aumento de produtividade, redução de custos e melhoria da qualidade, ao lado da metodologia sistêmica voltada para o desenvolvimento integrado, colocam-se como fatores indispensáveis na visualização de alternativas de saída para a atual crise em que está imersa a sociedade brasileira. A melhoria da qualidade de vida da população vincula-se, nos cenários utilizados, à alavancagem do sistema produtivo de bens e serviços, em termos quantitativos e qualitativos.

A década de 90 prenuncia-se como uma época de grandes transformações econômicas e sociais em todo o mundo, acarretando uma reordenação das áreas de influência dos principais paises desenvolvidos, com reflexos inevitáveis em nosso País. 
De um lado, há a emergência de novos paíse industrializados do extremo oriente, com uma interação cada vez maior com a economia norte-americana. De outro lado, ocorre a consolidação dos diversos países europeusem um únicobloco, com a eliminação de todas as barreiras alfandegárias a partir de 1992, provocando um novo ciclo de "renascimento". Este panorama é completado pela modernização e pela maior abertura econômica e política que se vem firmando nos países do bloco socialista.

O Brasil, como uma economia dependente, deverá posicionar-se diante dessa nova configuração, estabelecendo prioridades para modernizar-se e manter a competitividade em setores selecionados. Em um nível mais amplo, a integração de mercados latino-americanos, ainda muito menos significativa do que a dos megamercados europeu, americanoasiático e socialista, parece ser um imperativo políticoeconômico para a próxima década. Tal integração tem implicações que transcendem aos acordos formais econômicose políticos, afetando, de modo direto, a organização da indústria, suas operações e o desenvolvimento tecnológico.

No plano interno, prevê-se um avanço da democratização, com um revigoramento da empresa privada, fortalecimento da economia de mercado e menor influência do governo. Assim, o peso relativo das empresas estatais na economia deverá reduzir-se, com a emergência de novos atores no cenário futuro. A pequena e a média empresa moderna, tecnologicamente avançadas e competitivas, deverão ter uma participação cada vez maior.

No que se refere à economia regional, haverá uma maior desconcentração espacial, com uma participação relativamente maior das regiões Norte, Nordeste e Centro-oeste, indicando que os caminhos da Engenharia de Produção também devam seguir essa tendência.

\section{INTERNACIONALIZAÇÃO E MODERNIZAÇÃO DA ECONOMIA}

O processo de crescente engajamento do País no cenário internacional, que se acentuou a partir da década de 50 , deverá prosseguir de forma acelerada durantea década de 90. Isso exigirá, naturalmente, uma modernização do parque industrial, para manter a sua competitividade em nível mundial. Para isso, não será suficiente o País continuar oferecendo mão-de-obra barata no mercado mundial, pois este fatoré um recurso superabundante no mundo e a situação tende a agravar-se com a emergência de novos países industrializados. Deverá, isto sim, ser capaz de produzir, cada vez mais, produtos dealta qualidade a preços competitivos, visando, inclusive, o mercado dos países desenvolvidos, dos países da América Latina, além do mercado interno. Isso terá reflexos sobre os sistemas produtivos, que deverão modernizar-se para atender às exigências cada vez mais sofisticadas dos consumidores, levando em conta as novas divisões do mercado mundial e as vantagens comparativas na produção.

\section{AVANÇOS TECNOLÓGICOS E MEIO AMBIENTE}

A introdução de novas tecnologias, como informática, telecomunicações, automação, biotecnologia e outras, provocará mudanças radicais no sistema produtivo, exigindo grandes esforços na área de formação de recursos humanos e organização da produção, para fazer face a esses novos desafios. As unidades de produção deverão ser mais integradas, flexíveis, compactas e menos poluentes, com profundos reflexos sobre os modelos de organização da produção, programaçãoe controle da produção e estoques, política de produto e de qualidade, e assim por diante. A preservação e a recuperação do meio ambiente são preocupações de crescente importância na próxima década. 


\section{EXIGÉNCIAS DE QUALIDADE E FLEXIBILIDADE}

As novas tecnologias exigirão novos padrões de qualidade que, por sua vez, exigirão maior qualificação do pessoal produtivo e gerencial. O aumento do poder aquisitivo e do nível de informação da sociedade em geral provocarão demanda por artigos diversificados e de melhor qualidade, que possam se adaptar melhor às exigências dos consumidores e trabalhadores. Portanto, nessa nova fase, não será suficiente produzir artigos baratos e massificados, mas será necessárioatentar, cada vez mais, para as necessidades e as peculiaridades do consumidor, exigindoadaptações do sistema produtivo para atender a essas novas características do mercado.

\section{EXPANSÃO HORIZONTAL}

O processo de modernização não se restringirá ao setor industrial, mas deverá permear também para os setores primário e terciário da economia. Isso significa dizer que haverá um engajamento cada vez maior da Engenharia de Produção em atividades agrícolas e de serviços, como educação, transportes, construção civil e outras. O enfoque sistêmico adotado inicialmente em situações industriais será cada vez maisaplicado em outras áreas, como abastecimento e sistemas de informações.

\section{PEQUENAS E MÉDIAS EMPRESAS}

Deverá haver uma diminuição da dicotomia hoje existente que coloca, de um lado, as grandes empresas do setor moderno $e$ competitivo e, de outro lado, as empresas pequenas e médias, tecnologicamente atrasadas, produzindo artigos de qualidade inferior e pagando baixos salários. Deverá surgir uma nova geração de pequenas e médias empresas, com tecnologias modernas, ágeis eflexíveis, bastante competitivas, principalmente no mercado de peças e componentes e na prestação de serviços. Com isso, poderá surgir um novo e promissor mercado para a atuação daEP, que deverá se adaptara esse novo desafio, desenvolvendo técnicas e metodologias adequadas para isso. $\mathrm{O}$ apoio às microempresas, através de modelos simplificados de gerenciamento da produção, também deve ser incorporado à EP.

\section{REMODELAGEM DAS ORGANIZAÇÕES}

A acelerada taxa de mudanças tecnológicas nos produtos e processos industriais de alguns setores exigirá uma organização mais ágil. As organizações clássicas, dos tipos taylorista e fordista, serão substituídas por formas mais flexiveis e dinâmicas. Esse processo exigirá uma melhor qualificação do trabalhador e uma maior autonomia em sua atuação, principalmente dos "trabalhadores do conhecimento" ('knowledge workers').

Resultarão novos conceitos de organização do trabalho, com a expansão relativa do pessoal que ocupa cargos de níveis médios da hierarquia das empresas. A tendência atual de maior influência eparticipação dos trabalhadores e suas entidades de classe nas decisões das empresas deverá perdurar ou se acentuar na próxima década.

$O$ envolvimento do engenheiro de produção nessa remodelagem da organização deverá crescer, aumentandoa importância dos seus conhecimentos sobre organização do trabalho e planejamento estratégico empresarial.

\section{CONDICIONAMENTOS POLÍTICO-SOCIAIS}

Neste final de década alastram-se pelo mundo movimentos democráticos e ecológicosque terão grandes repercussões nos anos 90 . $O$ sindicalismotambém aparece reconhecidoe fortalecido. A consciência de cidadania enfrenta com maior vigor as injustiças sociais incrustadas especialmente no terceiro mundo. 
A busca da melhoria da qualidade de vida é a tônica principal desta virada de século. $O$ consumidor passa a questionar a qualidade de produtos e serviços exigindo melhores desempenhos. O trabalhador redobra sua luta por maiores salários e melhoria nas condições de trabalho.

Todas essas transformações recomendam uma reflexão sobre os caminhos futuros da Engenharia de Produção. Parece que uma simples extrapolação do passado já nãoé suficiente. Não se trata, também, de promover uma expansão quantitativa da base atualmente existente, com o expediente, por exemplo do aumento do número de vagas dos cursos atuais. Essa expansão exigirá muito mais, com uma ação coordenada em nível nacional, para a conjugaçăo de esforços e o direcionamento dos recursos para atender a determinadas prioridades. Um acompanhamento contínuo através de mecanismos institucionalizados se faz necessário para garantir a implementação das recomendações.

\section{Posicionamento da EP no Cenário Futuro}

Os avanços tecnológicos geralmente se referem aos progressos do "hardware", ou seja, aqueles incorporados nas máquinas, nos equipamentos e nos processos. Entretanto, estes não operam satisfatoriamente se não forem acompanhados de uma adequação da estrutura gerencial e dos recursos humanos. É na tecno logia de organização desses fatores que a EP pode dar uma contribuiçăo mais significativa.

A internacionalizaçãoda economia provoca demandas sobre atividades de melhoria da qualidade industrial e aumento de produtividade. Essas são áreas onde a Engenharia de Produção tem atuado tradicionalmente. A EP pode também trazer contribuições na i- dentificação de atividades industriais onde o Brasil possui maiores vantagens comparativas, no mercado internacional, através da análise de projetos industriais. Ela podecontribuir, ainda, com análises para subsidiar a tomada de decisões estratégicas sobre política industrial. Com sua abordagem ampla e diversificada, ela está em condições de fazer a seleção e acelerar a absorção de novas tecnologias, promovendo a liga ção entre os aspectos tecnológicos e as suas conseqüências humanas e econômicas, dentro do sistema produtivo. Isso complementa as habilidades de outras áreas da engenharia, como mecânica, elétrica, civil e química, cujas abordagens são predominantemente técnicas, não considerando, adequadamente, os aspectos humanos e recursos econômicos. Por outro lado, complementa as abordagens da Administraçãoe da Economia que tendem a ser muito genéricas, colocando em segundo plano os aspectos tecnológicos.

A maior agilidadeea eficácia na resposta às crescentes exigências de qualidade emelhor adequação dos produtos ao mercadoé uma preocupação constante da subárea de Engenharia do Produto da EP, que atua de forma complementar ao Desenho Industrial. Enquanto este ocupa-se do produto como objeto, a EP contribui para introduzi-lo no sistema produtivo da empresa e traça políticas e estratégias do desempenho deste no mercado, com estudos sobre custos, preços e distribuição.

O processo de modernização, que tem o seu foco no setor secundário (industrial), deverá irradiar-se rapidamente para os setores primário (agrícola) e terciário (serviços). A EP não poderia deixar de seguir esse itinerário. Assim, entre os desafios da próxima década estará aquele de adaptar as técnicas e metodologias da EP às aplicações agrícolas e aos serviços. Por exemplo, pode-se produzir economias razoáveis com a raciona- 
lização de insumos agrícolas ou com um correto dimensionamento e uma distribuição dos armazéns. Da mesma forma a construção civil, responsável por cerca de 7\% do Produto Interno Bruto e $30 \%$ da absorção da mão-deobra masculina do setor industrial, uma vez aplicados os conceitos de Engenharia de Produção, poderá utilizar com maior eficácia os recursos da sociedade.

O engajamento da EP nas pequenas e médias empresas exigirá uma adaptação dos seus enfoques tradicionais, geralmente ligados a empresas de grande porte, tecnologicamente complexas e com estruturas gerenciais diversificadas em um grande número de funções. Novas empresas de porte médio e pequeno, tecnologicamente avançadas e competitivas, exigirão a aplicação de metodologias adequadas. Devido à simplicidade gerencial e à sua reduzida capacidade financeira, aliada à necessidade de respostas rápidas, essas empresas exigirão uma aturação da EP a baixo custo produzindo efeitos a curto prazo, com a difusão de "pacotes" gerenciais de fácil implantação. $O$ envolvimento de alunos de graduação, através de trabalhos e estágios, pode levar as técnicas deEP ao nível de simplicidade das microempresas, gerando programas gerenciais e despertando vocações de novos empresários.

Enfim, as rápidas mudanças tecnológicas demandarão uma profunda reformulação de vários conceitos sobre sistemas produtivos. $\mathrm{Na}$ prática, isso dependerá de um entendimento maior das interações entre as mudanças tecnológicas com os seus aspectos econômicos, organizacionais, sociais, psicológicos e estratégicos. $O$ crescente interesse da EP em pesquisas sobre os impactos da mudança tecnológica deverá perdurar na próxima década e evoluir no sentido da elaboração de propostas de medidas técnicas, sociais e econômicas para resolver os problemas emergentes como os de saúde do trabalhador, poluição ambiental e riscos de catástrofes.

\section{Recomendações}

As recomendações propostas a seguir constituem-se em diretrizes para ordenar o desenvolvimento da Engenharia de Produção na década de 90 , fornecendo orientações para atuação das instituições existentes na área, de modo que seu conjunto se constitua em um sistema integrado e coerente.

\section{FORMAÇÃO DE RECURSOS HUMANOS}

$\mathrm{Na}$ formação profissional em nível de graduação em EP existem grandes vazios que necessitam ser preenchidos. Regiões inteiras como o Nordeste, o Norte e o Centro-oeste ainda não possuem cursos de graduação na área. Mesmo nas regiōes Sul e Sudeste existem estados de grande desenvolvimento econômico que não oferecem graduacão pesa área.

Em nível de pós-graduação, embora também ocorram deficiências de ordem geográfica, já é possível recomendar que o mestrado deva ser feito no Brasil, ficando a alternativa deestudos no exterior para odoutoramento. Para reforçar o posicionamento da pós-graduação, recomenda-se a alocação de recursos para auxiliar nas dissertaçōes e teses, administrados pelos respectivos cursos. As bolsas de apoio técnico também necessitam ser utilizadas neste contexto.

É necessário intensificar o apoio para a organização decursos de curta duração (cerca de 100 horas de atividades), em certos centros de pós-graduação no País, para atualizações de docentes e pesquisadores, principalmente em épocas de férias escolares. Esses cursos deverão ser ministrados preferencialmente por pesquisadores que tenham realizado importantes contribuições para o avanço da Engenharia de Produção ou que dominem importantes conhecimentos ainda pouco difun- 
didono País e por convidados doexterior de reconhecida competência.

\section{CRIAÇÃO DE CURSOS E} APRIMORAMENTO DOS EXISTENTES

Considerando-se que o total dos 26 cursos de EP hoje existentes (16 de graduação, 7 de mestrado e 3 de doutorado) é insuficiente para atender à futura demanda de profissionais da área, recomenda-se uma expansão para aumentar em cerca de $40 \%$ a capacidade atualmente existente, sem sacrificar os padrões de qualidade.

$\mathrm{Na}$ criação de novos cursos deverão ser consideradas as necessidades do mercado de trabalho. Comoeste se volta principalmente para o setor produtivo, a prioridade de expansão deverá recair sobre os cursos de graduação, onde se formam os profissionais adequados para atender a esse segmento do mercado. Já a expansão de oportunidades para docentes e pesquisadores não deverá seguir o mesmo ritmo. Assim, os atuais cursos de mestradoe doutorado deverão ser acrescidos somente daqueles já em fase de criação. Por outro lado, devemos considerar que os cursos de pós-graduação existentes ainda apresentam deficiências qualitativas, cuja superação se coloca em maior prioridade do que uma expansão em número que, de qualquer forma, não poderá ocorrer sem um expressivo aumento do número de doutores disponíveis no País.

Deverão ser incentivados os cursos de pósgraduação latosensu, em níveis de extensão, aperfeiçoamento e especialização, atendendo a demandas específicas. Para esse tipo de curso, deve-se buscar maior colaboração do setor produtivo.

Na medida do possível, recomenda-se que a criação de novos cursos seja feita mediante convênios de cooperação com aqueles centros já consolidados (COPPE/UFRJ, PUC) RJ, UFSC, USP).

\section{NOVOS CURSOS PROPOSTOS}

Atendendo basicamente aos critérios de mercadoe de desconcentração regional, são propostos novos cursos completando a rede de ensino já existente (ver Quadro 1):

a) Cursos de Graduação: implantar um curso nas regiōesSul,Nordeste, NorteeCentrooeste,

b) Cursos de Mestrado: implantar um curso adicional nas regiöes Sul, Sudeste eNordeste;

c) Cursos de Aperfeiçoamento e Especialização: deverão ser criados atendendo a necessidades específicas.

\section{APRIMORAMENTO DE CURSOS}

O aprimoramento dos cursos deverá ser feito pela modernização dos seus conteúdos, adaptação regional, melhorias didáticas e aprimoramento dos docentes. $O$ aperfeiçoamento dos conteúdos deve incluir notadamente o uso de apoio computacional, novos conceitos de organização do trabalho, estratégia empresarial, gestão social, qualidade total e aspectos profissionais da EP. A adaptação curricular às diferenças regionais deve ser feita em função das características econômicas, ambientais e sócio-culturais de cada região. Os novos métodos didáticos podem incluir o uso de vídeos, microcomputadores e demais facilidades, além da organização de ensino programado e estágios supervisionados. Devem ser reforçados os cursos de doutoramento do País, favorecendo a ampliação do número de vagas e a diversificação das áreas de concentração.

\section{CAPACITAÇÃO DE DOCENTES}

Há necessidade de aumentar consideravelmente o número de docentes, duplicandose, pelo menos, sua quantidade nos próximos 10 anos. O esforço para continuar titulando os atuais docentes deverá também prosseguir com maior intensidade, colocando-se uma meta de pelo menos 20 novos doutores a cada ano, sendo desejável titular pelo menos a 
metade destes no exterior. Recomenda-se uma diversificação maior na formação de docentes, enviando-os para países e instituições com excelência no tema de estudo e com os quais ainda se tenha pouco contato. $O$ processo de orientação de candidatos, da seleção de instituições, assim como a rigorosa seleção de candidatos e acompanhamento dos mesmos são essenciais. Sem isso, os benefícios desse esforço podem se tornar insignificantes. Deve ser também implementada uma firme política de fixação de docentes junto às universidades. A utilização de bolsas de produtividade é um mecanismo recomendado neste sentido.

Recomenda-se a criação de incentivo, aos docentes, para participarem de cursos de curta e média duração (1 a 12 meses), assim como para realizarem estágios no Brasil e no exterior, principalmente nas "áreas prioritárias de atuação" (especificadas a seguir), $\theta \mathrm{em}$ outras áreas interdisciplinares.

\section{FORMAÇÃO COMPLEMENTAR NO EXTERIOR}

O doutoramento no País, envolvendo uma formação parcial no exterior, apresenta destacada importância na área de Engenharia de Produção. Dentre todas asengenharias, aEP é aquela que mais necessita de uma forte vinculação coma realidade local e uma acentuada pertinência social. Programas baseados em convênios de colaboração interinstitucional envolvendo a participação de co-orientadores do exterior, respaldados na interveniência de agências de fomento, podem ser instrumentos de alta eficácia na fase de consolidação do doutoramento em EP no Brasil.

\section{ATUALIZAÇÃo DE DOCENTES E PESQUISADORES}

Deverão ser criadas oportunidades para atualização de docentes e pesquisadores, visando a rápida absorção de novos métodos, procedimentos e tecnologias.
Os docentes titulados há mais de cinco anos deverão ter oportunidades de reciclagem em estágios e cursos de curta duração, no Brasil ou no exterior. As prioridades para pósdoutoramento (para recém-doutores no País ou para pesquisadores em licença sabática)no exterior e no País deverão ser mantidase expandidas.

As atividades de pós-doutoramento deverão ser priorizadas, tanto no País comoespecialmente no exterior. As uportunidades para absorção de recém-doutorados e pesquisadores em licença sabática também necessitam ser expandidas. Dentro das características da $\mathrm{EP}$, as iniciativas de integração UniversidadeEmpresa devem ser apoiadas com a implementação de mecanismos específicos.

\section{ÁREAS PRIORITÁRIAS DE ATUAÇÃo}

São considerados prioritários para atualização e pesquisa os seguintes tópicos:

a) Gerência da Produção: novas formas de organização da produção, aplicação de técnicas como Kanban, Just-in-time, sistemas flexíveis e gestão social;

b) Engenharia de Produto: política do produto, lançamento de novos produtos, análise de custos e de valor, requisitos ergonômicos;

c) Qualidade e Confiabilidade Industrial: qualidade total, qualidade de projeto, organização para a qualidade, análise dedesempenho;

d) Informatização: informatização do processo produtivo, dos sistemas de distribuição e comercialização, sistemas de apoioà decisão e sistemas especialistas;

e) Gestão da Inovação: automação, CAD/ CAM/CIM, robótica, telemática, análise de erros incidentes, confiabilidade humana, desenvolvimento, absorção e negociação de transferência de novas tecnologias; 
f) Gestão da Pequena e de Média Empresa: adaptação de metodologias e técnicas gerenciais de produção, treinamento para modernização e aspectos organizacionais;

g) Pesquisa Operacional: tratamento de incerteza, novas técnicas computacionais, integração com a inteligência artificial;

h) Melhoria das Condições de Trabalho e de Vida dos Trabalhadores: estudo dos acidentes, carga fisica e mental do trabalho, gerência de riscos e catástrofes;

i) Engenharia Econômica: análise de projetos industriais, subsídios para elaboração de estratégias e políticas de desenvolvimento.

\section{APOIO À PESQUISA E COLABORAÇÃ̃O INTERINSTITUCIONAL}

Deve ser garantida a continuidade daquelas pesquisas de maior vulto e de prazos mais longos, realizadas por equipes estruturadas.

Emáreas ou regiões ainda poucodesenvolvidas, mas consideradas promissoras, devem ser apoiados grupos emergentes, com critérios diferenciados mas sem concessões quanto à excelência.

Considera-se essencial o aumento do númerodebolsas de iniciação científica e aperfeiçoamento científico para incentivar o aparecimento de novos talentos.

Considera-se desejável o desenvolvimento de linhas de pesquisa mais integradas, em nível nacional, pela coordenação de esforços entre as diversas instituições que atuam em áreas semelhantes, no sentido de se alcançar resultados mais significativos e sua efetiva transferência para a sociedade. Novos incen- tivos à ccoperação técnica e ao intercâmbio de docentes devem ser desenvolvidos.

Deverá ser intensificada a cooperação com o setor produtivo, tanto na realização de estágios, como no desenvolvimento de projetos para resolver problemas industriais e na extensão universitária.

\section{DIFUSÃO DE CONHECIMENTOS}

Considera-se que os conhecimentos gerados pela pesquisa não terão cumprido o seu papel enquanto não forem difundidos, através de mecanismos apropriados, em cooperação com centros de pesquisa e desenvolvimento regionais e setoriais e associações de classe, a fim de tornar o processo de repasse de conhecimento mais eficaz e mais abrangente. Comoessa difusão envolve atividades e serviços especializados, não pode ficar simplesmente a cargo dos próprios pesquisadores. Assim, propõe-se a criação e o fortalecimento dos seguintes meios:

\section{EVENTOS}

Os eventos periódicos, organizados pelas associações científicas como a ABEPRO, a SOBRAPO e a ABERGO, são ocasiões onde ocorre uma ampla troca de informações entre os pesquisadores e destes com os demais membros da comunidade. Propõe-se que o apoio concedidoa organização desses eventos seja mantido como uma das prioridades da área.

\section{REVISTA DE ENGENHARIA DE PRODUÇÃO}

Considera-se importante a criação de uma revista de Engenharia de Produção, de circulação nacional, tendo o objetivo principal de difundir métodos, técnicas e casos práticos de aplicações, junto ao setor produtivo, veiculando também notícias e resenhas de teses, livros, pesquisas e demais atividades da área. 


\section{LIVROS DIDÁTICOS}

Devese incentivar o autor nacional, principalmente naquelas matérias dos cursos de graduação onde ainda não existe bibliografia satisfatória, pela concessão de bolsas especiais a docentes e pesquisadores que se habilitem a preparar originais de livros didáticos.

\section{BANCO DE DADOS EM \\ ENGENHARIA DE PRODUÇÃO}

Considera-se desejável organizar um banco de dados e publicar, bianualmente, um catálogo coletivo em Engenharia de Produção, contendo informações sobre todos os cursos, pesquisas, docentes e demais atividades desenvolvidas na área de EP e nas áreas conexas

\section{PLANEJAMENTO, \\ ACOMPANHAMENTO \\ E AVALIAÇÃO}

Recomenda-seque:

a) a política nacional de pós-graduação e pesquisa seja compativel com as necessidades regionais;

b) o processo de acompanhamento e avaliação dos programas de pós-graduação deva ser norteado pelos seguintes requisitos: transparência, agilidade, periodicidade, maior orientação após as avaliações, estabilidade e constância nos critérios de avaliação, a poio aos grupos emergentes.

Como uma das recomendações mais importantes deste documento, sem a qual todos os outros esforços poderão ser inócuos, propõe-se a criação de um grupo permanente de acompanhamento e avaliação da área, com as seguintes atribuições:

a) atualizar, anualmente, o Programa de Desenvolvimento da Engenharia de Produção; b) elaborar os Planos Anuais de Ação da Área, encaminhando-se às agências de fomento e aos centros de ensino e pesquisa nela atuante;

c) incentivar e orientar cada instituiçãoa elaborar planos anuais de atuação próprios, contendo metas referentes ao ensino, pesquisa, extensão, infra-estrutura, formação e atualização dos recursos humanos;

d) supervisionar a organização de um banco de dados em EP, em cooperação com a CAPES e as Associações Científicas da área, mantendo informaçōes cadastrais atualizadas sobre os cursos, pesquisas, docentes, pesquisadores, eventos e demais atividades;

e) avaliar, anualmente, o desempenho da área, elaborando um relatório para ser discutido durante os Encontros Nacionais organizados pelas Associações Científicas a ser encaminhado às agências de fomento e de coordenação;

f) sugerir a organização de atividades de interesse coletivo como seminários, workshops, cursos de curta-duração e estágios;

g) assessorar órgãos do governo, emitindo pareceres e encaminhando sugestões sobre ações para implementar as recomendações contidas neste documento.

\section{Conclusões}

Com a implantação do Programa de Désenvolvimento de Engenharia de Produção, pretende-se modernizar e fortalecer essa área de ensino e pesquisa, revertendo a tendência de quase estagnação que se verificou nos últimos 15 anos. Caso seja mantida esta tendência, a organização e a capacidade de formar novos elementos não serão suficientes para responder a um novo surto de desenvolvimento econômico e aos novos desafios colocados pelo avanço da tecnologia no 
próximo decênio. Corre-se o risco de esvaziamento das universidades e dos centros de pesquisa, com a evasão de docentes e pesquisadores para o mercado de trabalho, em condições mais atraentes, se o precário equilibrio atual for rompido. Não há, no momento, estoque de elementos suficientes, em formação, para repor essas possíveis perdas. Além do mais, considerando-se que a formação de recursos humanos para docência e pesquisa exige pelo menos de 5 a 10 anos para que possa atingir resultados efetivos, é necessário que seja iniciada imediatamente.

Cabe, finalmente, uma recomendação especial às agências de fomento: que se faça uma provisão orçamentária e se criem mecanismos especiais que privilegiem as atividades de interesse coletivo, que tendam a aumentar o nível de informação, organização e coesão da comunidade que atua na área, procurando ainda fortalecer e ampliar as interações e iniciativas conjuntas com o setor produtivo, suas associações de classe e seus centros de pesquisa e de desenvolvimento. Considera-se que esse tipo de atividade complementa aquelefomentodecaráter individualizadoe contribui para seu melhor aproveitamento.

Em especial, ao CNPq propõese a efetivação do grupo de acompanhamento e a designação de um supervisor técnico para apoiar as atividades do referido grupo, $\mathrm{e}$ a responsabilidade pela organização de um banco de dados em Engenharia de Produção.

\section{Referências Bibliográficas}

1. BNDES. Área de Planejamento. Departamento de Planejamento. Síntese dos $\mathrm{Ce}$ nários para a Economia Brasileira: 19872000.

2. LUSTOSA, L. e IIDA, I. Programa Nacional de Engenharia de Produção. CNPq, 1989. 


\begin{tabular}{|c|c|c|c|c|c|c|}
\hline REGIÃO & \multicolumn{2}{|c|}{ ESTADO } & GRADUAÇĀO & MESTRADO & DOUTORADO & TOTAL \\
\hline \multirow[t]{2}{*}{ SE } & \multirow{2}{*}{ SP } & Capital & $\begin{array}{l}\text { EPUSP } \\
\text { FEI } \\
\text { IEEP }\end{array}$ & EPUSP & EPUSP & 5 \\
\hline & & Interior & $\begin{array}{l}\text { UFSCar } \\
\text { EESC } \\
\text { UNIMEP } \\
\text { F.E. Bauru } \\
\text { E.E. Guarating. }\end{array}$ & & & 5 \\
\hline SE & \multicolumn{2}{|c|}{ Rio de Janeiro } & UFRJ & $\begin{array}{l}\text { UFRJ } \\
\text { PUC/RJ } \\
\text { UFF }\end{array}$ & UFRJ & 6 \\
\hline \multirow[t]{2}{*}{ SE } & \multicolumn{2}{|c|}{ Minas Gerais } & $\begin{array}{l}\text { UFMG } \\
\text { EFEI Itajubá }\end{array}$ & & & 2 \\
\hline & \multicolumn{2}{|c|}{ Espírito Santo } & UFES & & & 1 \\
\hline S & \multicolumn{2}{|c|}{ Santa Catarina } & UFSC & UFSC & UFSC & 3 \\
\hline S & \multicolumn{2}{|c|}{ Rio Grande do Sul } & UCS & UFSM & & 2 \\
\hline NE & \multicolumn{2}{|c|}{ Paraíba } & & $\mathrm{UFPb}$ & & 1 \\
\hline \multicolumn{3}{|c|}{ TOTAL } & 15 & 7 & 3 & 25 \\
\hline
\end{tabular}

Obs.: O IME atua no mestrado e o ITA atua no mestrado e no doutorado em subáreas da Engenharia de Produção, sem uma caracterização explícita da área.

Quadro 1. Distribuição regional dos cursos existentes de Engenharia de Produção 


\section{SIGLAS DAS INSTITUIÇÕES}

E.E.Guarating. - Escola de Engenharia de Guaratinguetá (Universidade Estadual de São Paulo)

EESC - Escola de Engenharia de São Carlos (Universidade de São Paulo)

EFEI Itajubá - Escola Federal de Engenharia de Itajubá

EPUSP - Escola Politécnica da Universidade de São Paulo

F.E. Bauru - Faculdade de Engenharia Industrial

FEI - Faculdade de Engenharia Industrial - SP

IEEP - Instituto de Ensino de Engenharia Paulista

IME - Instituto Militar de Engenharia - RJ

ITA - Instituto Tecnológico de Aeronáutica SP
INPE/São José dos Campos - Instituto de Pesquisas Espaciais

PUC/RJ - Pontifícia Universidade Católica do Rio de Janeiro

UCS - Universidade de Caxias do Sul

UFES - Universidade Federal do Espírito Santo

UFF - Universidade Federal Fluminense

UFMG - Universidade Federal de Minas Gerais

UFSCar - Universidade Federal de São Carlos

UNIMEP - Universidade Metodista de Piracicaba

UFPb - Universidade Federal da Paraíba

UFRJ - Universidade Federal do Rio de Janeiro

UFSC - Universidade Federal deSanta Catarina

UFSM - Universidade Federal de Santa Maria 